\title{
Phase Current Reconstruction of Switched Reluctance Motors from DC-Link Current Under Double High Frequency Pulses Injection
}

\author{
Chun Gan, Student Member, IEEE, Jianhua Wu, Shiyou Yang, and Yihua Hu, Member, IEEE
}

\begin{abstract}
Switched reluctance motors (SRMs) have been considered as low-cost machines for electric vehicle (EV) and hybrid electric vehicle (HEV) applications. However, the current sensors used in the system will not only increase the cost and volume, but also degrade the running reliability of the motor drives. Conventionally, the current sensors are used in each phase winding individually to obtain these phase currents. To reduce the number of current sensors, a four-phase $8 / 6$-pole SRM is applied to analyze the working states and a novel phase current reconstruction method from the dc-link current employing double high frequency pulses injection is then proposed. Two kinds of high frequency pulses with large dutycycles and phase-shift are injected to the down-switches in each phase respectively when the phase currents are overlapped in the turn-on region, and the dc-link current is decomposed to reconstruct phase currents in both current chopping control (CCC) system and single pulse control (SPC) system. The transient performance in a closed-loop system based on the phase current reconstruction scheme is investigated. The proposed method uses only one current sensor in the dc-link and requires no additional circuits. The simulation and experimental results are presented to confirm the implementation of the proposed method.
\end{abstract}

Index Terms-Switched reluctance motor (SRM), electric vehicle (EV), phase current reconstruction, high frequency pulses injection, single current sensor, dc-link current.

\section{INTRODUCTION}

$\mathrm{I}$ N RECENT years, the electric vehicles (EVs) and hybrid electric vehicles (HEVs) have attracted ever increasing attentions because of the rapid depletion of energy resources and increasing environmental awareness [1]-[3]. The permanent-magnet synchronous motor (PMSM) is the most popular electrical motor in applications of EVs and HEVs [4], [5]. However, a PMSM generally requires the use of permanent magnets, typically fabricated from rare-earth materials such as neodymium and dysprosium. The high cost and poor stability in high temperatures associated with the rare-earth materials have limited its wide application in EVs and HEVs.

Manuscript received May 30, 2014; revised August 8, 2014; accepted September 14, 2014.

Copyright (c) 2014 IEEE. Personal use of this material is permitted. However, permission to use this material for any other purposes must be obtained from the IEEE by sending a request to pubs-permissions@iee.org.

This work was supported in part by the National Nature Science Foundation of China (51377139).

C. Gan, J. Wu, and S. Yang are with the College of Electrical Engineering, Zhejiang University, Hangzhou 310027, China (e-mail: ganchun.cumt@163.com; hzjhwu@163.com; shiyouyang@yahoo.com).

$\mathrm{Y}$. $\mathrm{Hu}$ is with the Department of Electronic \& Electrical Engineering, University of Strathclyde, Glasgow, UK. (e-mail: Yihua.hu@strath.ac.uk)
To provide an ideal drive for EVs and HEVs, more efforts have been devoted to the development of alternative motors using less or no rare-earth materials. The switched reluctance motor (SRM) has a simple structure without any rotor windings and permanent magnets. As a result, the motor has the capability of long service time under harsh environments due to its rugged structure [6]. It is demonstrated that a SRM has many advantages, to name but a few, such as high efficiency, low cost, high reliability, excellent fault tolerance operation, and high starting torque for initial acceleration. Consequently, it is considered as the potential candidate for applications in EVs and HEVs [7]-[14]. However, to promote the application of SRMs in EVs and HEVs, the following two issues should be properly addressed: 1) the optimal design of the motor stator and rotor; 2) the optimizations of the control scheme.

In the control issues, the main approaches used for SRM drives can roughly be categorized into current chopping control (CCC) [15], single pulse control (SPC) [16], and direct torque control (DTC) [17]. Sensorless control is another hot topic in this direction due to its reduced cost and enhanced reliability of the motor drives, especially in high temperatures or high speed operation. Some sensorless control methods for startup and steady-state operations are proposed and detailed in [18]-[20]. A high frequency pulse injection is usually employed to implement sensorless control in existing methodologies. In most applications, SRMs are used with simultaneous excitation of more than one phase for continuous torque production. The dynamic process of twophase excitation of SRM is analyzed in the current control mode and single pulse mode [21]. In [22], a hybrid excitation method with two-phase excitation by long dwell angle as well as conventional one-phase excitation is proposed to reduce vibration and acoustic noise in the SRM drives.

As for an EV or HEV drive, phase currents are very important parameters for current control and fault protection in the motor system. However, a compact, low-cost and highperformance motor drive is needed. The system cost and volume can be reduced greatly within only a current sensor, which will make the product more compact. Moreover, the unbalanced voltage drop can also be eliminated due to the different voltage gains of the current sensors. The literatures related to phase current reconstruction or one current sensor control technologies for PMSM, brushless dc (BLDC) motor, induction motor (IM) and SRM are given in [23]-[31].

A new type of single current sensor technique with an online current offset compensation function is proposed for 
three-phase inverter applications without severe distortion in [23]. Switching-state phase shift is proposed based on the pulse width modulation (PWM) pattern modification to realize three-phase current reconstruction for PMSM servo drives in [24]. The control methods under the overmodulation mode with only a dc-link current sensor for PWM-inverter-fed interior PMSM drives are investigated in details in [25]. A novel method for IM phase current reconstruction is presented with a single Hall-effect current sensor in three-phase direct matrix converter drive system using space vector modulation control technique [26], [27]. In [28], the waveform error that is present in line current signals, which are reconstructed in IM drives using a single dc-link shunt, is analyzed. A new DTC scheme for IM drives using a single dc-link sensor is proposed in [29], and the results show the excellent performance of the drive. In [30], a control strategy based on a single current sensor is proposed for a four-switch three-phase BLDC motor drive to lower cost and improve performance. In [31], a dc-link current control method is proposed for three-phase SRM systems. A complex logic function is employed to control the power switches using additional hardware circuits, while the effective method of the current sampling for phase current reconstruction is not put forward. However, the insertion of the sensing states easily leads to current waveforms distortion, and the current hysteresis control cannot be implemented effectively.

This paper is focused on using fewer current sensors to reduce the cost, volume and weight of the SRM drives for EVs and HEVs. A four-phase 8/6-pole SRM with complex phase current overlapping states is employed to analyze phase currents under different turn-on regions, and a novel SRM phase current reconstruction method from the dc-link current using double high frequency pulses injection is proposed in this paper. In the two-phase excitation region, two kinds of high frequency pulses with phase-shift and large duty-cycles are injected to every down-switch respectively, and two analog to digital (A/D) converters are triggered in PWM pause middles, which realizes the synchronization between the high frequency pulses and the A/D samplings. The simulations and experiments are carried out in both CCC and SPC systems, and the transient performance of the closed-loop system based on the phase current reconstruction is demonstrated. The proposed method only needs a single current sensor and two A/D converters without any additional circuits to obtain high quality reconstructed phase currents. The simulation and experimental results are presented to confirm the feasibility of the proposed methodology.

\section{Phase Currents And Proposed Phase Current RECONSTRUCTION SCHEME}

\section{A. SRM Drive}

A SRM drive is mainly composed of a SRM, a power converter, a drive circuit, a position detection circuit and a current sampling circuit, etc, as shown in Fig. 1. The phase current sampling process is an important part in high performance control schemes. Many control schemes for
SRMs can be implemented through the sampled phase currents directly, such as CCC and DTC schemes.

A typical asymmetric half-bridge converter is usually adopted in the SRM drive. Each bridge arm is controlled independently by two switches and each phase is independent of each other, providing good stability and fault tolerance ability. The current flows back in full negative voltage when $S_{1}$ and $S_{2}$ both shut off. The energy flows back to power supply quickly, which is advantageous to phase commutation. To reduce the torque ripple and the switching loss, it usually adopts a control mode that only up-switch chops and downswitch remains closed in the phase turn-on region.

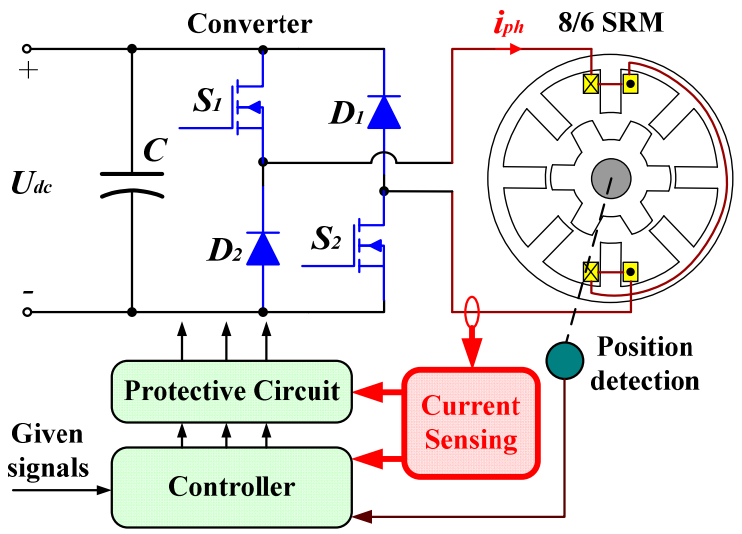

Fig. 1. 8/6-pole SRM drive system.

For example of phase A, $S_{1}$ chops and $S_{2}$ remains closed in the phase turn-on region, and the energy is supplied to phase A immediately, in which state, when $S_{1}$ and $S_{2}$ are both on, phase A winding suffers from the positive dc-link voltage, $U_{\mathrm{dc}}$, as shown in Fig. 2(a). When $S_{1}$ is off and $S_{2}$ is on, the phase voltage is zero, as shown in Fig. 2(b). $S_{1}$ and $S_{2}$ both shut off in the phase turn-off region, the phase current flows back to power supply through diodes $D_{1}$ and $D_{2}$, and phase A winding suffers from the negative dc-link voltage, $-U_{\mathrm{dc}}$, as shown in Fig. 2(c).

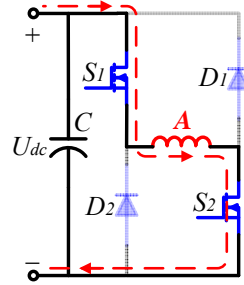

(a)

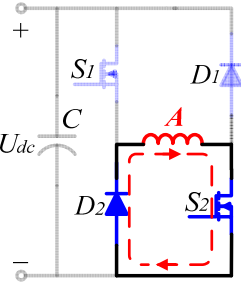

(b)

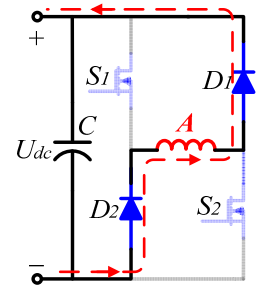

(c)
Fig. 2. Operation modes of the converter. (a) $S_{1}$ on, $S_{2}$ on (excitation mode). (b) $S_{1}$ off, $S_{2}$ on (free-wheeling mode). (c) $S_{1}$ off, $S_{2}$ off (demagnetization mode).

\section{B. Phase Currents}

DC-link current is the sum of all phase currents, and the current hysteresis control scheme is implemented to these phase currents in the phase turn-on region in CCC system. There are two states of phase currents in a two-phase excitation region: overlap and non-overlap, as shown in Figs. 3 and 4. However, only two phase currents are overlapped at most. In the figures, $S_{1}, S_{3}$ and $S_{7}$ are the driving signals for the up-switches of phase A, B and D respectively; $S_{2}, S_{4}$ and $S_{8}$ are the driving signals for the down-switches of phase A, 
$\mathrm{B}$ and $\mathrm{D}$ respectively; $i_{\mathrm{a}}, i_{\mathrm{b}}$ and $i_{\mathrm{d}}$ are phase $\mathrm{A}, \mathrm{B}$ and $\mathrm{D}$ currents respectively.

Taking phase A current for example, Fig. 3 shows the state of two phase currents non-overlap in the turn-on region. $\theta_{1}$ is the turn-on angle and $\theta_{4}{ }^{\prime}$ is the turn-off angle of phase A, satisfying

$$
\theta_{4}{ }^{\prime} \leq \theta_{1}+15^{\circ}
$$

Region I is the excitation interval, and Region II is the demagnetization interval of phase A. There are no overlapping regions between down-switch signals of phase A, $\mathrm{D}$, and B, i.e., $S_{2}, S_{8}$, and $S_{4}$. Only excitation current of phase $\mathrm{A}$ and demagnetization current of phase $\mathrm{D}$ are contained in the rotor position region of $\theta_{1}-\theta_{4}$, where the excitation current is controllable phase current, and the demagnetization current is uncontrollable phase current. The CCC scheme aims at phase current in turn-on region to implement current hysteresis control, needing excitation current, as shown in Fig. 2(a)-(b); without the need of demagnetization current, as shown in Fig. 2(c). Therefore, if the demagnetization current is not contained in the dc-link current, the sampled dc-link current is considered to be phase A current in Region I, and every phase current can be reconstructed in terms of turn-on and turn-off regions of each phase.

For the state of two phase currents non-overlap in the turnon region, the dc-link current can be regulated directly to implement the CCC scheme or current protection.

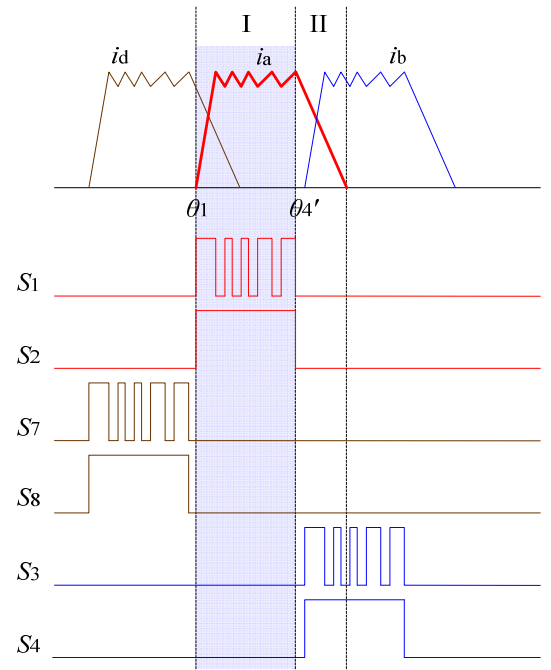

Fig. 3. Two phase currents non-overlap in the turn-on region.

Fig. 4 shows the state of two phase currents overlap in the turn-on region. $\theta_{1}, \theta_{4}$ and $\theta_{5}$ are the turn-on angle, turn-off angle, and current ending angle of phase A respectively, $\theta_{2}$ is the turn-off angle of phase $\mathrm{D}$, and $\theta_{3}$ is the turn-on angle of phase B. In this state, $\theta_{1}$ and $\theta_{4}$ satisfy

$$
\theta_{4}>\theta_{1}+15^{\circ}
$$

Since the difference between the turn-on and turn-off angles of each phase is the same, the overlapping regions of Region I and III are all equal to $\triangle \theta$, and Region I III are related to the turn-on interval of phase A. Similarly, if the demagnetization current is not contained in the dc-link current, Region I is the current overlapping region of phase $\mathrm{A}$ and $\mathrm{D}$, and the dc-link current is the sum of phase A and D currents; only excitation current of phase A is contained in the dc-link current in Region II; Region III is the current overlapping region of phase $\mathrm{A}$ and $\mathrm{B}$, and the dc-link current is the sum of phase A and B currents; only excitation current of phase B is contained in the dc-link current in Region IV, in which phase A current is the demagnetization current. Hence, the dc-link current excluding the demagnetization current can be expressed as (3) in the rotor position region of $\theta_{1}-\theta_{5}$ :

$$
i_{d c}=\left\{\begin{array}{lc}
i_{d}+i_{a}, & \theta_{1}<\theta \leq \theta_{2} \\
i_{a}, & \theta_{2}<\theta \leq \theta_{3} \\
i_{b}+i_{a}, & \theta_{3}<\theta \leq \theta_{4} \\
i_{b}, & \theta_{4}<\theta \leq \theta_{5}
\end{array}\right.
$$

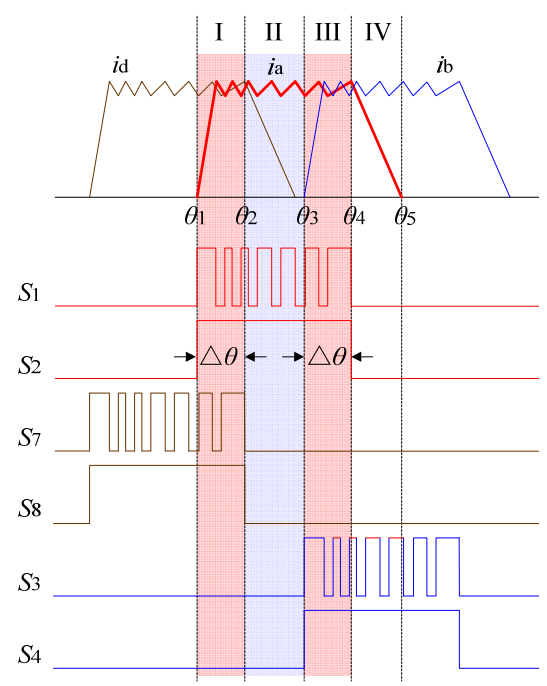

Fig. 4. Two phase currents overlap in the turn-on region.

\section{Proposed Phase Current Reconstruction Scheme}

The conventional phase current sampling method is to install a current sensor in each phase winding, respectively, using some individual $\mathrm{A} / \mathrm{D}$ converters to identify these currents simultaneously, as illustrated in Fig. 5. The current sensors used in the system add the cost and volume to the motor drives.

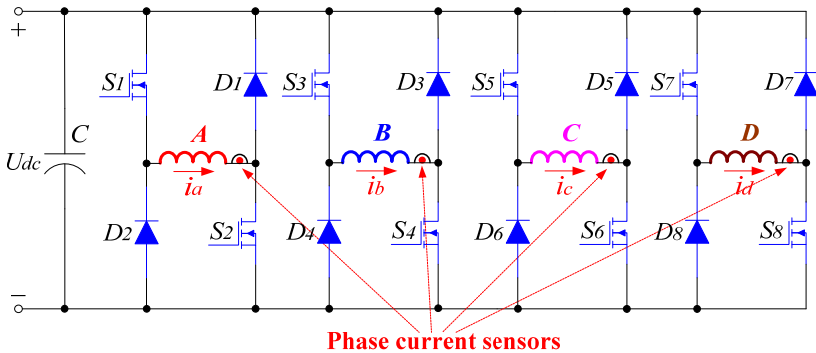

Fig. 5. Conventional current sampling method in a four-phase system.

In this paper, a novel current sensing method in the dc-link is proposed to reconstruct every phase current through decomposing the dc-link current in the turn-on region. The dc-link current sampling position is illustrated in Fig. 6. As shown in the figure, all positive poles of the down-diodes are connected together to the down dc-link, and all sources of the down-switches are also connected together to the down dclink through a current sensor; hence, all demagnetization 
currents are not contained and only the sum of all excitation currents are contained in the sampled dc-link current.

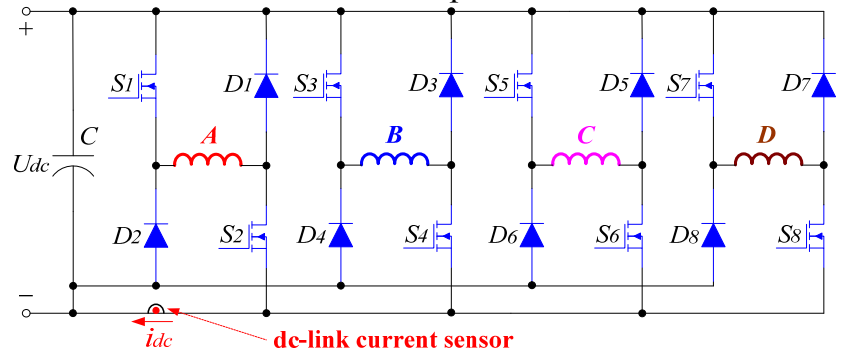

Fig. 6. DC-link current sampling method.

The switching functions of the converter are defined as

$$
S_{2,4,6,8}= \begin{cases}1, & \text { Down-switch is on } \\ 0, & \text { Down-switch is off }\end{cases}
$$

The dc-link current is expressed in terms of phase currents and switching functions as

$$
i_{d c}=i_{a} S_{2}+i_{b} S_{4}+i_{c} S_{6}+i_{d} S_{8}
$$

The relationship between the dc-link current and the converter switching states in the phase excitation sequence is presented in Table I. There are, at most, three switching states when phase A current is contained in the dc-link current.

TABLE I

RELATIONSHIP BETWEEN DC-LINK CURRENT AND SWITCHING STATES

\begin{tabular}{ccccc}
\hline $\boldsymbol{S}_{\mathbf{2}}$ & $\boldsymbol{S}_{\mathbf{4}}$ & $\boldsymbol{S}_{\boldsymbol{6}}$ & $\boldsymbol{S}_{\mathbf{8}}$ & $\boldsymbol{i}_{\mathbf{d c}}$ \\
\hline 1 & 0 & 0 & 0 & $i_{\mathrm{a}}$ \\
1 & 1 & 0 & 0 & $i_{\mathrm{a}}+i_{\mathrm{b}}$ \\
0 & 1 & 0 & 0 & $i_{\mathrm{b}}$ \\
0 & 1 & 1 & 0 & $i_{\mathrm{b}}+i_{\mathrm{c}}$ \\
0 & 0 & 1 & 0 & $i_{\mathrm{c}}$ \\
0 & 0 & 1 & 1 & $i_{\mathrm{c}}+i_{\mathrm{d}}$ \\
0 & 0 & 0 & 1 & $i_{\mathrm{d}}$ \\
1 & 0 & 0 & 1 & $i_{\mathrm{d}}+i_{\mathrm{a}}$ \\
\hline
\end{tabular}

If two phase currents are not overlapped in excitation regions, the dc-link current is apparently the phase current in the phase turn-on region, and all phase currents can be obtained directly by multiplying the dc-link current and driving signals without any high frequency pulses injection.

If two phase currents are overlapped in excitation regions, one will take phase A current reconstruction for example. As shown in equation (3), the dc-link current in Region I is the sum of phase A and D currents. At this point, if the downswitch of phase D is shut off, the dc-link current is only phase A current; if the down-switch of phase A is shut off, the dc-link current is only phase D current. However, only phase A current is contained in the dc-link current in Region II. In Region III, the dc-link current is the sum of phase A and $B$ currents. Thus, if the down-switch of phase B is shut off, the dc-link current is only phase A current; if the downswitch of phase A is shut off, the dc-link current is only phase B current.

Therefore, the dc-link current in the overlapping region of $\theta_{1}-\theta_{2}$ can be expressed as

$$
i_{d c}= \begin{cases}i_{a}, & S_{2}=1, S_{8}=0 \\ i_{d}, & S_{2}=0, S_{8}=1\end{cases}
$$

The dc-link current in the overlapping region of $\theta_{3}-\theta_{4}$ can be expressed as

$$
i_{d c}= \begin{cases}i_{a}, & S_{2}=1, S_{4}=0 \\ i_{b}, & S_{2}=0, S_{4}=1\end{cases}
$$

In order to reconstruct phase A current, the high frequency pulse, PWM_1, with a large duty-cycle is injected to the down-switches of phase D and B in the overlapping Region I and III, and an A/D converter channel, A/D_1, is triggered to sample the dc-link current in the PWM_1 pause middle, which can reconstruct phase A current in Region I and III. Since the dc-link current in Region II is the phase A current, the sampled current in Region I III is the reconstructed phase A current in the turn-on region.

Similarly, in order to reconstruct phase D current in Region I and phase B current in Region III, an additional high frequency pulse, PWM_2, with the same duty-cycle and some phase-shift from PWM_1 is required to be injected to the down-switch of phase A in Region I and III, and another A/D converter channel, A/D_2, is triggered to sample the dclink current in the PWM_2 pause middle.

Double high frequency pulses and A/D sampling instants in overlapping regions of phase $\mathrm{A}$ and $\mathrm{B}$, and phase $\mathrm{A}$ and $\mathrm{D}$ are shown in Fig. 7. PWM_1 and PWM_2 are shifted by $t_{\text {shift }}$.

Defining $t_{\text {shift }}$ as a half period of PWM_1,

$$
t_{\text {shift }}=\frac{t_{\text {on }}+t_{\text {off }}}{2}
$$

The PWM duty-cycle, $D_{\mathrm{PWM}}$, is expressed as

$$
D_{P W M}=\frac{t_{\text {on }}}{t_{\text {on }}+t_{\text {off }}}
$$

where $t_{\text {on }}$ and $t_{\text {off }}$ are the turn-on and turn-off times in a period of the high frequency pulse, respectively.

The frequencies and duty-cycles of the injected PWMs should be large enough to ensure that the dc-link current can be sampled with a high precision. However, due to the sensing tolerance of the current sensors, the maximum dutycycle values should be limited considering the fact that the dc-link sensor has sufficient time to measure the current.

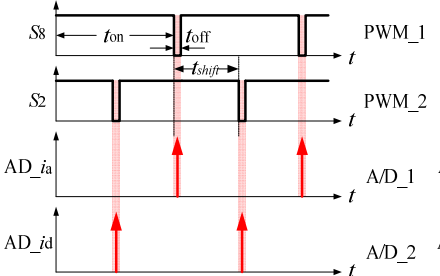

(a)

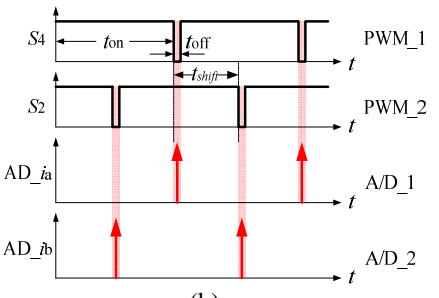

(b)
Fig. 7. High frequency pulses and A/D sampling instants using a single current sensor in the dc-link. (a) Currents overlapping region of phase A and D. (b) Currents overlapping region of phase A and B.

Fig. 8 shows the diagram of the double high frequency pulses injection modes. High frequency pulse, PWM_1, is injected to the down-switches of phase $\mathrm{B}$ and $\mathrm{D}$ respectively; meanwhile, high frequency pulse, PWM_2, is injected to the down-switches of phase $\mathrm{A}$ and $\mathrm{C}$ respectively to implement phase current reconstruction for phase A, B, C, and D. 


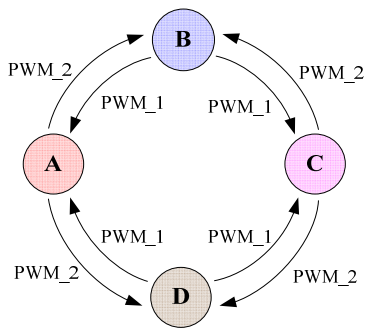

Fig. 8. Diagram of the double high frequency pulses injection modes.

In this diagram, $B \stackrel{\text { PWM_1 }}{\longrightarrow} A$ represents injecting high frequency pulse, PWM_1, to the down-switch of phase B in the overlapping region of phase $\mathrm{A}$ and $\mathrm{B}$, and triggering the $\mathrm{A} / \mathrm{D}$ converter, $\mathrm{A} / \mathrm{D} \_1$, to sample the dc-link current in the PWM_1 pause middle to reconstruct the phase A current.

Likewise, $A \stackrel{\mathrm{PWM}_{2} 2}{\longrightarrow} B$ represents injecting high frequency pulse, PWM_2, shifted by $t_{\text {shift }}$ from PWM_1, to the down-switch of phase $\mathrm{A}$ in the overlapping region of phase $\mathrm{A}$ and $\mathrm{B}$, and triggering the $\mathrm{A} / \mathrm{D}$ converter, $\mathrm{A} / \mathrm{D}$ 2, to sample the dc-link current in the PWM_2 pause middle to reconstruct the phase $\mathrm{B}$ current.

From the analysis above, the four phase currents are completely reconstructed by the following equation:

$$
\left[\begin{array}{l}
i_{a_{-} r e} \\
i_{b_{-} r e} \\
i_{c_{-} r e} \\
i_{d_{-} r e}
\end{array}\right]=\left[\begin{array}{cccc}
S_{2} & 0 & 0 & 0 \\
0 & S_{4} & 0 & 0 \\
0 & 0 & S_{6} & 0 \\
0 & 0 & 0 & S_{8}
\end{array}\right] \cdot\left[\begin{array}{c}
i_{d c_{-} a} \\
i_{d c_{-} b} \\
i_{d c_{-} c} \\
i_{d c_{-} d}
\end{array}\right]
$$

where $\left\{\begin{array}{l}i_{d c_{-} a}=i_{d c_{-} c} \\ i_{d c_{-} b}=i_{d c_{-} d}\end{array}, i_{\mathrm{a}_{-} \mathrm{re}}, i_{\mathrm{b}_{-} \mathrm{re}}, i_{\mathrm{c}_{-} \mathrm{re}}\right.$ and $i_{\mathrm{d}_{-} \mathrm{re}}$ are the reconstructed phase currents, $i_{\mathrm{dc} \_\mathrm{a}}, i_{\mathrm{dc} \_\mathrm{b}}, i_{\mathrm{dc} \_\mathrm{c}}$ and $i_{\mathrm{dc} \_\mathrm{d}}$ are the sampled dc-link currents with double high frequency pulses injection, and $S_{2}, S_{4}, S_{6}$ and $S_{8}$ are the regular driving signals.

\section{NUMERICAL SiMULATIONS}

To validate the feasibility of the proposed phase current reconstruction method, a $150 \mathrm{~W} 8 / 6$-pole SRM is employed to act as the case study of a nonlinear model of the motor system. The flux linkage and torque data of the motor obtained using ANSOFT software are used to implement the simulation model in MatLab/Simulink. The power converter is built by using the modules of SimPowerSystems, and the driving signals are generated from PWMs with logic outputs. Fig. 9 shows the current reconstruction modules in the overlapping region of phase A and D with the double high frequency pulses injection. As shown in the modules, $S_{2}$ and $S_{8}$ are the regular driving signals in the down-switches of phase A and D, while $S_{2 \text { new }}$ and $S_{8 \text { new }}$ are the exact driving signals output after injecting the double high frequency pulses (PWM_1 and PWM_2).

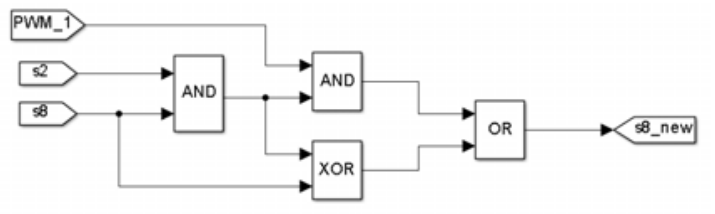

(a)

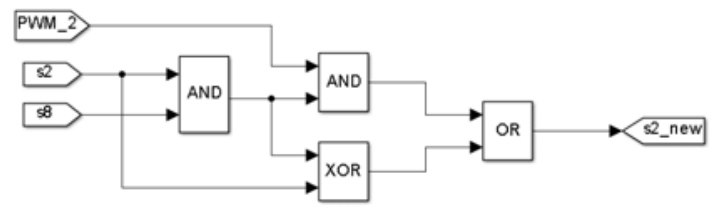

(b)

Fig. 9. Current reconstruction modules in the overlapping region of phase A and D. (a) Current reconstruction for phase A. (b) Current reconstruction for phase D.

In the CCC simulations, the dc-link voltage is fixed to 30 $\mathrm{V}$, the current reference is set to $0.73 \mathrm{~A}$, and the current hysteresis width is set to 0.03 A. Fig. 10 shows the dc-link current and the four phase currents in currents nonoverlapping and currents overlapping states in CCC system. In Fig. 10(a), the turn-on angle is set to $0^{\circ}$ and the turn-off angle to $15^{\circ}$, and the excitation phase currents are not overlapped in each turn-on region. At this point, the phase currents can be reconstructed directly according to the relationship of the turn-on region and the dc-link current without any high frequency pulses injection. In Fig. 10(b), the turn-on angle is set to $0^{\circ}$ and turn-off angle to $22^{\circ}$, and the two excitation phase currents have an overlap in the phase turn-on region. At this point, the dc-link current is the sum of the two overlapping phase currents, and the total phase currents in the turn-on region can be reconstructed by using the double high frequency pulses injection.

In order to reconstruct these phase currents in the overlapping regions, two kinds of high frequency pulses with phase-shift and large duty-cycles are injected to the downswitches respectively. The injected PWM frequencies are set to $10 \mathrm{kHz}$ and the duty-cycles are set to 0.95 . Fig. 11(a) shows the case that PWM_1 is injected to the down-switches of phase $\mathrm{B}$ and $\mathrm{D}$ in the overlapping region of phase $\mathrm{A}$ and $\mathrm{B}$, and phase $\mathrm{A}$ and $\mathrm{D}$ respectively to reconstruct the phase $\mathrm{A}$ current; Fig. 11(b) shows the case that PWM_2 is injected to the down-switch of phase $\mathrm{A}$ in the overlapping region of phase $\mathrm{A}$ and $\mathrm{D}$ to reconstruct the phase $\mathrm{D}$ current.

In the SPC simulations, the dc-link voltage is fixed to $12 \mathrm{~V}$. Fig. 12 shows the dc-link current and the four phase currents in currents non-overlapping and currents overlapping states in SPC system. In Fig. 12(a), the turn-on angle and the turnoff angle are set to $0^{\circ}$ and $15^{\circ}$, respectively. The two are set to $0^{\circ}$ and $22^{\circ}$ respectively in Fig. 12(b). Fig. 13 shows the dclink current, the phase currents, and the driving signals by using the double high frequency pulses injection method to reconstruct phase currents in SPC system.

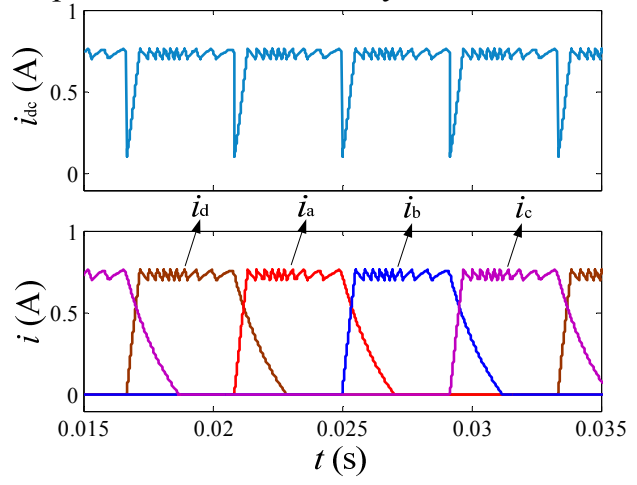

(a) 


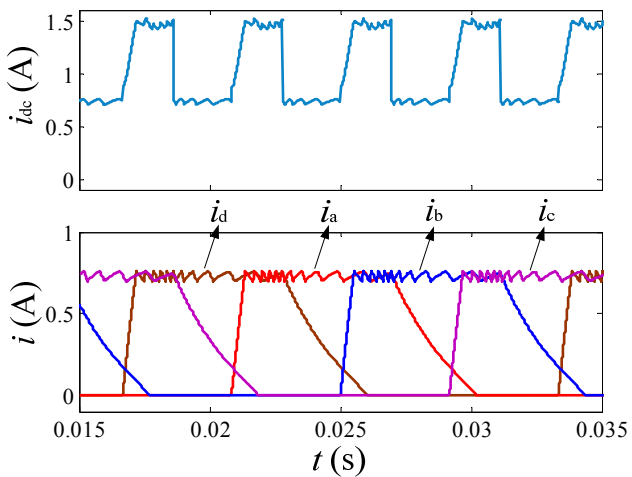

(b)

Fig. 10. DC-link current and phase currents before double high frequency pulses injection in CCC system. (a) Currents non-overlap. (b) Currents overlap.
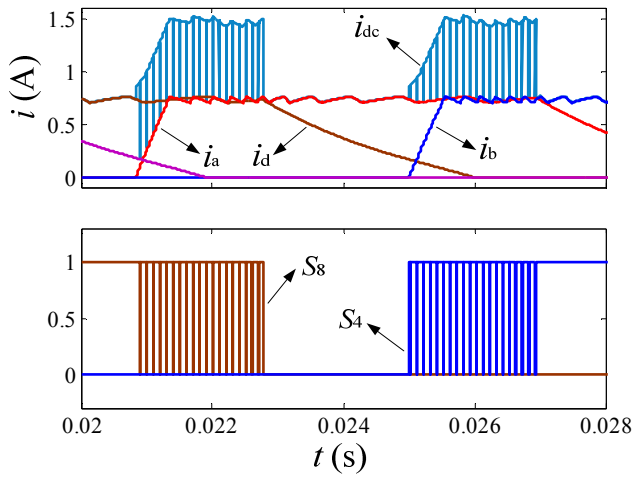

(a)

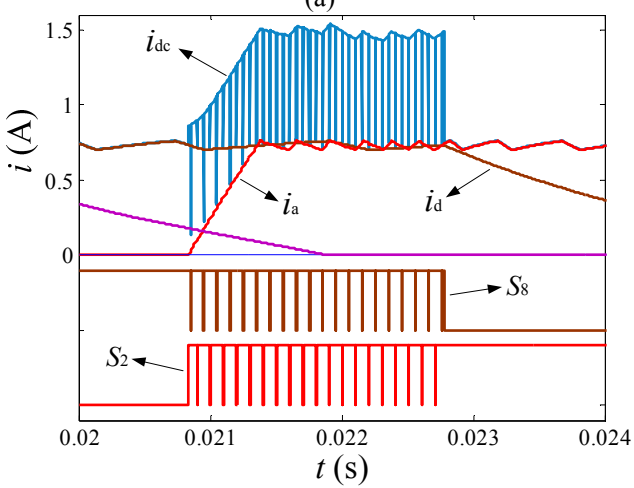

(b)

Fig. 11. Phase current reconstruction from double high frequency pulses injection in CCC system. (a) In the turn-on region of phase A. (b) In the overlapping region of phase $\mathrm{A}$ and $\mathrm{D}$.

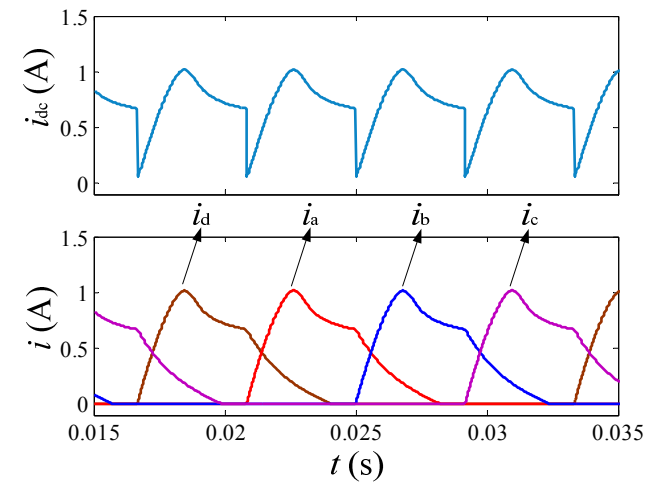

(a)

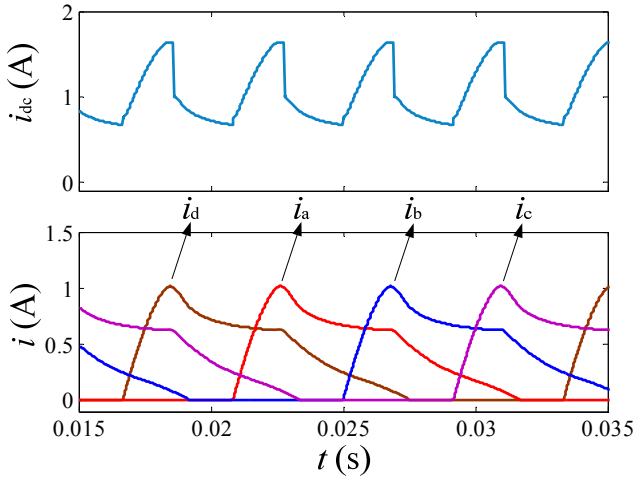

(b)

Fig. 12. DC-link current and phase currents before double high frequency pulses injection in SPC system. (a) Currents non-overlap. (b) Currents overlap.
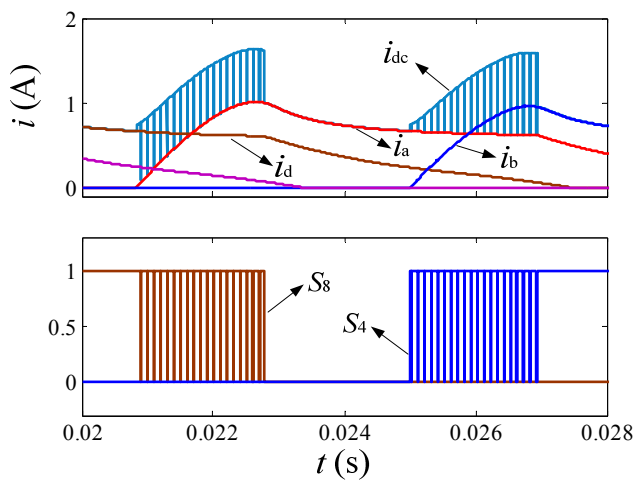

(a)

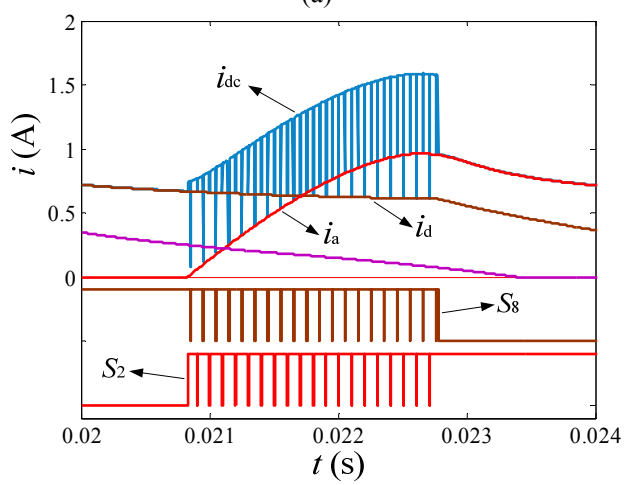

(b)

Fig. 13. Phase current reconstruction from double high frequency pulses injection in SPC system. (a) In the turn-on region of phase A. (b) In the overlapping region of phase $\mathrm{A}$ and $\mathrm{D}$.

According to the simulation results, the dc-link current pauses track the phase currents successfully in both CCC and SPC systems. Hence, the proposed phase current reconstruction method is feasible theoretically.

\section{EXPERIMENTAL RESULTS}

\section{A. Phase Current Reconstruction}

In order to validate the effectiveness of the proposed scheme further on the basis of the previous simulation results, a low power SRM is employed to build the experimental system, and the main experimental parameters are summarized in Table II.

The experimental system is schematically illustrated in Fig. 14. In the currents overlapping regions, the double high 
frequency pulses are injected to the down-switches, and the phase currents are reconstructed by sampling the dc-link current though the operational amplifiers and A/D sampling logic control with the driving signals of each phase. The reconstructed phase currents are directly controlled to implement a current hysteresis operation to realize CCC scheme based on the dc-link current sampling using a single current sensor.

The practical laboratory setup of the system is shown in Fig. 15. An adjustable regulated dc power supply is used in the system, the motor is driven by an asymmetric half-bridge converter, and the rotor position is obtained by using an incremental encoder. The dSPACE-DS1006 control board is employed as the main controller, with peripheral highspeed logic circuits in the setup. The dc-link current is measured from a Hall-effect current sensor (LA-55P) and simultaneously sampled by two 14-bit A/D converters for implementation of the proposed phase current reconstruction scheme. Four additional LA-55Ps are installed in the motor phases for comparison purposes.

\section{TABLE II}

EXPERIMENTAL PARAMETERS

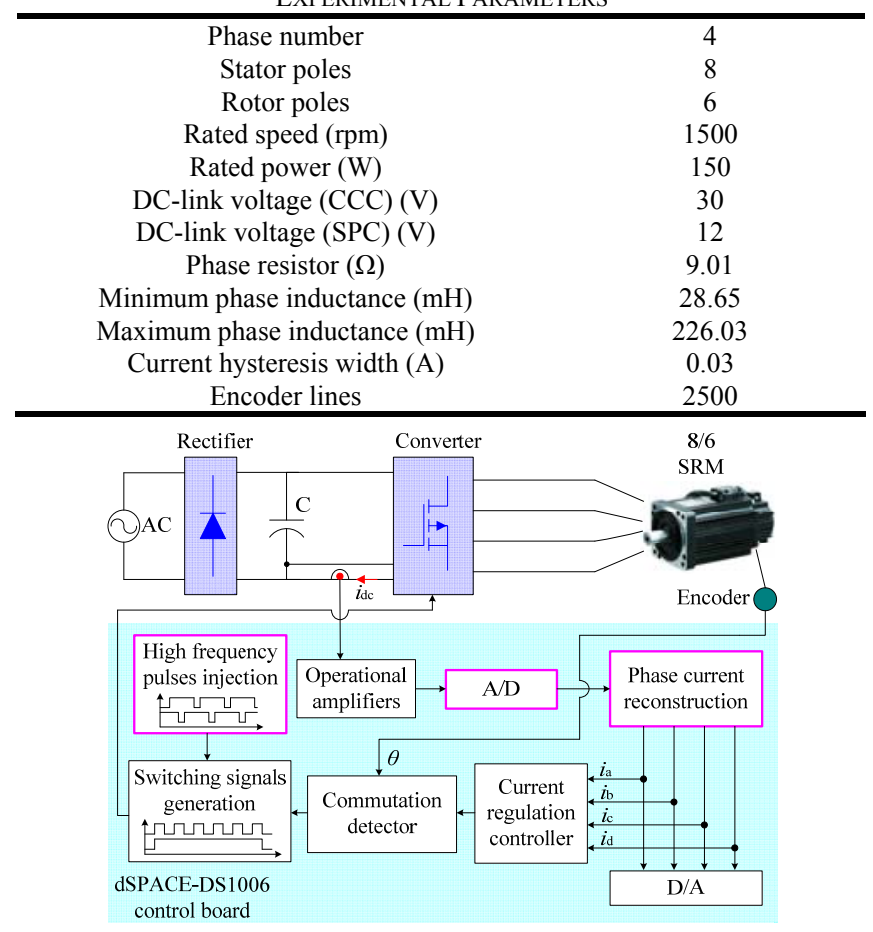

Fig. 14. Schematic diagram of the experimental system.

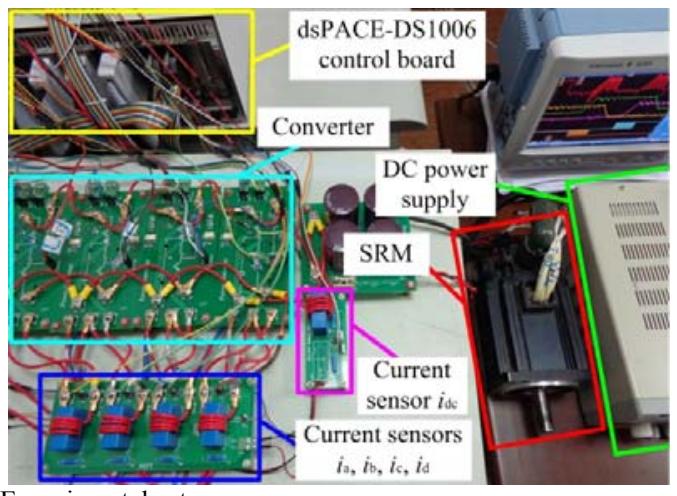

Fig. 15. Experimental setup.
In the experiments, the frequencies and duty-cycles of the double high frequency pulses are set to $10 \mathrm{kHz}$ and 0.95 respectively, being equal to those in the simulations, as shown in Table III. Two A/D converters are triggered to sample the dc-link current in the pause middle of the double high frequency pulses respectively.

\section{TABLE III}

Details of Double High Frequency Pulses For IMPLEMENTATION

\begin{tabular}{ccccc}
$f_{\mathrm{PWM}} 1$ & $f_{\mathrm{PWM}_{2} 2}$ & $D_{\mathrm{PWM}_{-} 1}$ & $D_{\mathrm{PWM}_{2}}$ & $t_{\text {shift }}$ \\
$10 \mathrm{kHz}$ & $10 \mathrm{kHz}$ & 0.95 & 0.95 & $50 \mu \mathrm{s}$ \\
\hline
\end{tabular}

Fig. 16 shows the dc-link current and the phase currents without high frequency pulses injection in CCC system. Fig. 16(a) shows the phase currents non-overlapping state, where the current reference is set to $1.1 \mathrm{~A}$, and the turn-on and turnoff angles are set to $0^{\circ}$ and $15^{\circ}$ respectively. Fig. 16(b) shows the phase currents overlapping state, where the current reference is set to $0.73 \mathrm{~A}$, and the turn-on and turn-off angles are set to $0^{\circ}$ and $22^{\circ}$ respectively.

Fig. 17 shows the dc-link current and the phase currents with high frequency pulses injection in CCC system. The current reference is set to $0.73 \mathrm{~A}$. Fig. 17(a) shows the currents and driving signals with PWM_1 injection. The lower envelope of the dc-link current is phase A current clearly, as illustrated in the figure. Phase A current in the excitation region can be reconstructed by triggering the A/D converter to sample the dc-link current in the PWM_1 pause middle. Fig. 17(b) shows the currents and driving signals with PWM_1 and PWM_2 injection. Phase A and D currents can be reconstructed by triggering two A/D converters to sample the dc-link current in the PWM_1 and PWM_2 pause middles respectively.

Figs. 18 and 19 show the dc-link currents, phase currents and driving signals without and with high frequency pulses injection in SPC system. The turn-on and turn-off angles are set to the same sequences as Figs. 16 and 17 depicted.

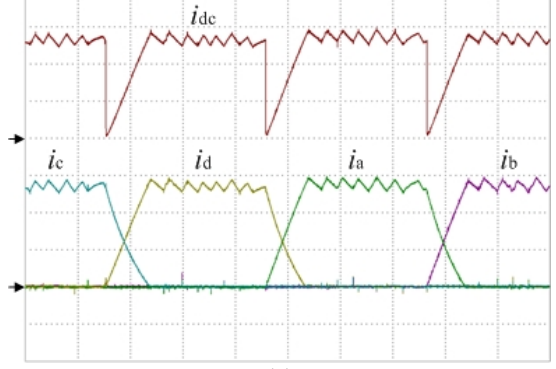

(a)

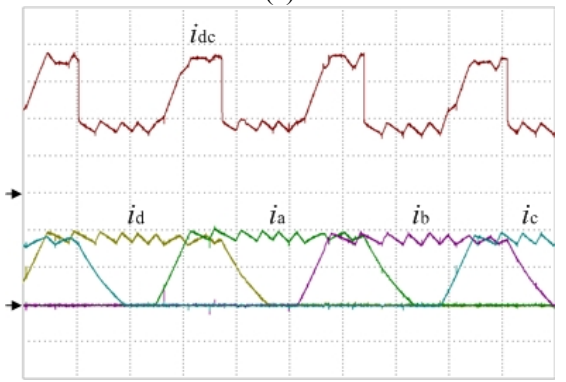

(b)

Fig. 16. DC-link current and phase currents before double high frequency pulses injection in CCC system $\left(i_{\mathrm{a}}, i_{\mathrm{b}}, i_{\mathrm{c}}, i_{\mathrm{d}}\right.$, and $i_{\mathrm{dc}}: 0.4 \mathrm{~A} / \mathrm{div}$; time: $\left.2 \mathrm{~ms} / \mathrm{div}\right)$. (a) Currents non-overlap. (b) Currents overlap. 
IEEE TRANSACTIONS ON INDUSTRIAL ELECTRONICS

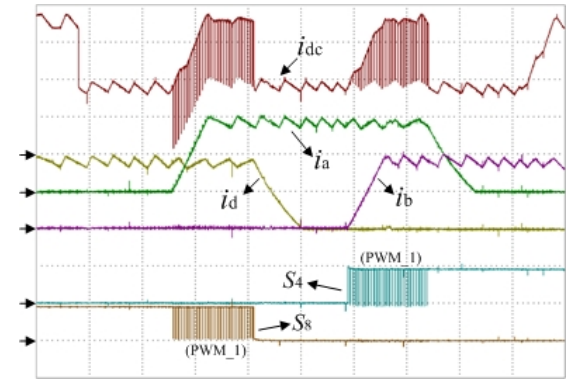

(a)

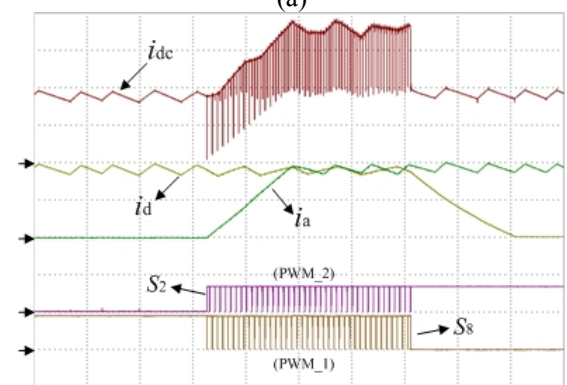

(b)

Fig. 17. Phase current reconstruction using double high frequency pulses injection in CCC system $\left(i_{\mathrm{a}}, i_{\mathrm{b}}, i_{\mathrm{c}}, i_{\mathrm{d}}\right.$, and $i_{\mathrm{dc}}: 0.4 \mathrm{~A} / \mathrm{div}$; time: $2 \mathrm{~ms} / \mathrm{div}$ for (a) and $1 \mathrm{~ms} /$ div for (b)). (a) Current reconstruction for phase A. (b) Current reconstruction for phase $\mathrm{A}$ and $\mathrm{D}$.

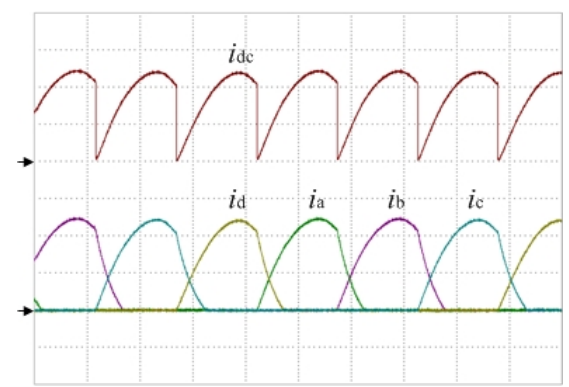

(a)

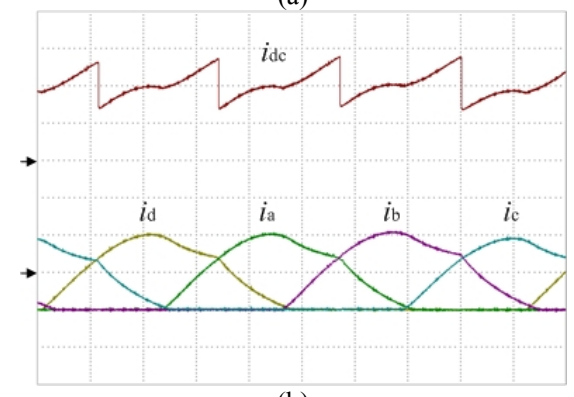

(b)

Fig. 18. DC-link current and phase currents before double high frequency pulses injection in SPC system $\left(i_{\mathrm{a}}, i_{\mathrm{b}}, i_{\mathrm{c}}, i_{\mathrm{d}}\right.$, and $i_{\mathrm{dc}}: 0.4 \mathrm{~A} / \mathrm{div}$; time: $5 \mathrm{~ms} / \mathrm{div}$ for (a) and $2 \mathrm{~ms} / \mathrm{div}$ for (b)). (a) Currents non-overlap. (b) Currents overlap.

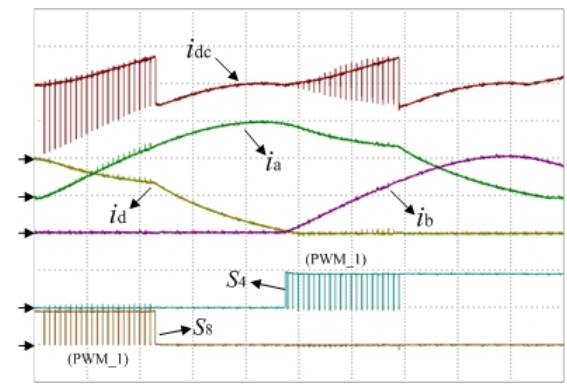

(a)

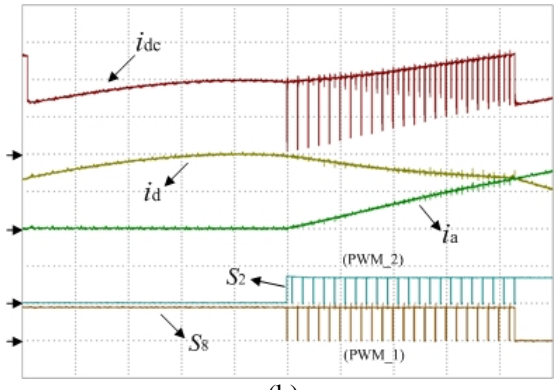

(b)

Fig. 19. Phase current reconstruction using double high frequency pulses injection in SPC system $\left(i_{\mathrm{a}}, i_{\mathrm{b}}, i_{\mathrm{c}}, i_{\mathrm{d}}\right.$, and $i_{\mathrm{dc}}: 0.4 \mathrm{~A} / \mathrm{div}$; time: $1 \mathrm{~ms} / \mathrm{div}$ for (a) and $0.5 \mathrm{~ms} / \mathrm{div}$ for (b)). (a) Current reconstruction for phase A. (b) Current reconstruction for phase $\mathrm{A}$ and $\mathrm{D}$.

The reconstructed phase currents are observed using a multichannel D/A converter with a low-pass filter, and compared with the sampled phase currents in Fig. 20. To compare the performance of the traditional sampling method using the individual current sensor and the proposed reconstruction method in the current reconstruction regions, an error metric, $e_{i a}$, of phase A current is defined as

$$
e_{i a}=i_{a_{-} r e}-i_{a}
$$

It is observed, from the experimental results, that the maximum errors are $0.02 \mathrm{~A}$ in $\mathrm{CCC}$ system and $0.015 \mathrm{~A}$ in SPC system, respectively. The reconstructed phase currents in the excitation regions successfully track the actual sampled currents, confirming that the proposed method can provide high quality current reconstruction. As a result of the large duty-cycle of the injected high frequency pulse, the turn-off time in a period of the injected PWM is extremely short, which has little impact on the phase current. Since the torque ripples are function of the phase currents and the noise is closely related to the phase currents, the proposed method will not increase the torque ripples and cause abnormal noise generation. Therefore, the CCC scheme is considered to be implemented through the dc-link current sampling using a single current sensor, which is expected to have the same performance as using four phase current sensors individually.

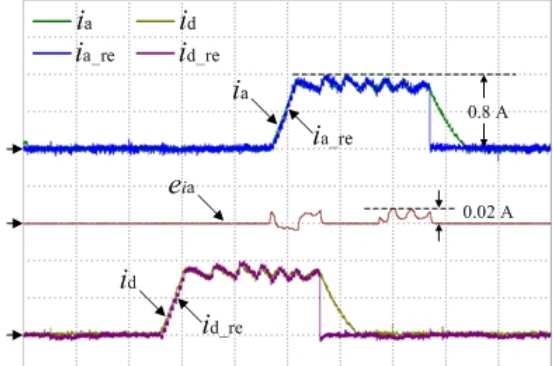

(a)

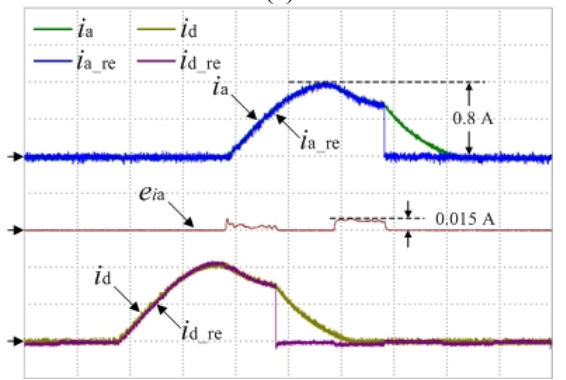

(b) 
Fig. 20. Comparison of the measured and reconstructed phase currents $\left(i_{\mathrm{a}}\right.$, $i_{\mathrm{a} \text { re }}, i_{\mathrm{b}}$ and $i_{\mathrm{b} \text { re }}: 0.4 \mathrm{~A} / \mathrm{div} ; e_{i \mathrm{a}}: 0.05 \mathrm{~A} / \mathrm{div} ;$ time: $2 \mathrm{~ms} / \mathrm{div}$ ). (a) CCC system. (b) SPC system.

\section{B. Closed-Loop System based on Phase Current Reconstruction}

In order to demonstrate the transient performance of the current control in the closed-loop system based on the proposed phase current reconstruction scheme using a single dc-link current sensor, the dc-link current is sampled to reconstruct phase currents, current hysteresis control is implemented to the reconstructed currents directly, and a proportional and integral (PI) controller is applied to control the motor speed.

Fig. 21 shows the dynamic speed responses and the transient progression of the closed-loop system based on the proposed phase current reconstruction method. The motor speed is stabilized within $100 \mathrm{~ms}$ and $400 \mathrm{~ms}$, respectively, when the motor speed rises from 600 to $900 \mathrm{rpm}$ and falls from 900 to $300 \mathrm{rpm}$. The instantaneous speed follows the given values well irrespective of low speed or high speed, despite speed changes during acceleration and deceleration, as shown in Fig. 21(a). When the load increases from no-load to $0.5 \mathrm{Nm}$ and 0.5 to $1 \mathrm{Nm}$, the speed will converge to it and is stabilized within $200 \mathrm{~ms}$, as shown in Fig. 21(b). Similarly, when the load reduces from 1 to $0.5 \mathrm{Nm}$ and $0.5 \mathrm{Nm}$ to noload, the speed is also responded within $200 \mathrm{~ms}$, as shown in Fig. 21(c). Hence, the developed system has good response ability to the load variations.

It should be noted that the chopping frequency is variable in a hysteresis control system. For the case study, the maximum value in the reconstruction regions varies from 1.23 to $1.65 \mathrm{kHz}$ under different speeds and loads, which is much smaller than $10 \mathrm{kHz}$. Moreover, the experimental result as given in Fig. 20(a) is obtained in an operating condition when the ripple frequency is $1.61 \mathrm{kHz}$, very close to the maximum frequency, guaranteeing the feasibility of the proposed scheme in a wide ripple frequency range of a hysteresis control system.

Fig. 22 shows the efficiency of the proposed control scheme and traditional method at $0.95 \mathrm{Nm}$ rated load. The measured efficiency is almost identical in the two control methods. Clearly, the efficiency is not degraded in the proposed system even though the current sensors are reduced.

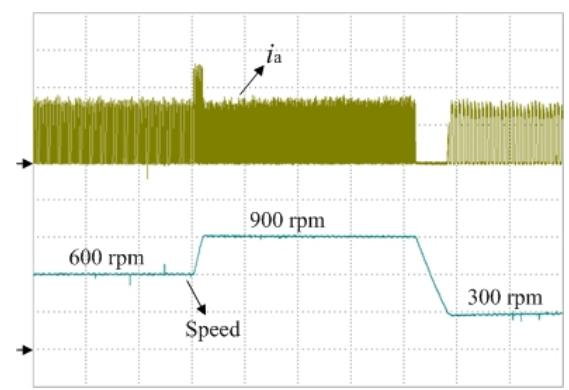

(a)

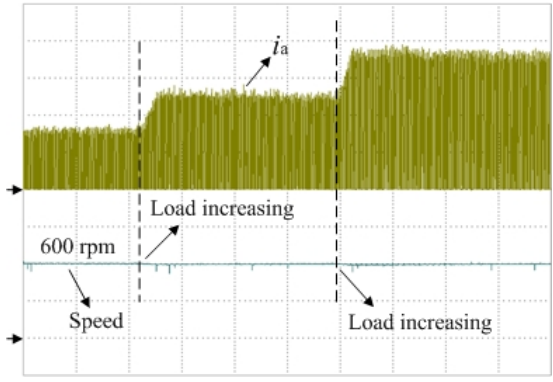

(b)

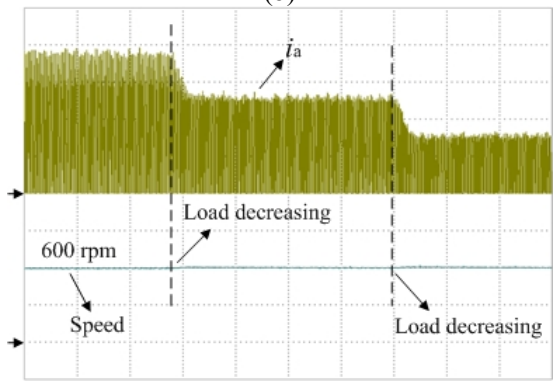

(c)

Fig. 21. Transient response of the closed-loop system based on phase current reconstruction ( $i_{\mathrm{a}}: 0.4 \mathrm{~A} / \mathrm{div}$; speed: $300 \mathrm{rpm} / \mathrm{div}$; time: $\left.500 \mathrm{~ms} / \mathrm{div}\right)$. (a) Acceleration and deceleration. (b) Continuous load increasing. (c) Continuous load decreasing.

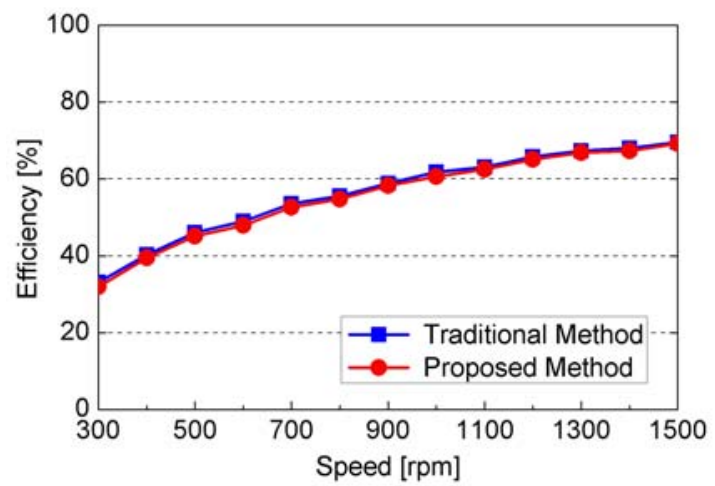

Fig. 22. Efficiency comparison.

\section{CONCLUSION}

In this paper, a proposal to design a compact SRM drive for EVs and HEVs is reported. The influence of different open intervals to phase currents of a SRM is analyzed, and the two states of currents overlap and currents non-overlap in the excitation region are presented and compared. A novel phase current reconstruction scheme for SRM based on the dc-link current sampling is proposed without current distortions in terms of currents overlapping state.

In the proposed method, the double high frequency pulses with phase-shift and large duty-cycles are injected to the down-switches in the two-phase excitation region, two A/D converters are triggered respectively in the PWM pause middle to sample the dc-link current, and all phase currents in the phase excitation regions are reconstructed effectively combining with the turn-on and turn-off information. The proposed method can realize the synchronization between the high frequency pulses and the $\mathrm{A} / \mathrm{D}$ samplings so as to obtain high quality reconstructed phase currents. The simulations and experiments are carried out in both CCC and SPC systems. The reconstructed phase currents successfully track 
the actual sampled currents without abnormal noise generation. Current hysteresis control in a closed-loop system based on the phase current reconstruction from the dc-link current using a single dc-link current sensor is implemented to demonstrate the dynamic speed responses and the transient progression to the load variations. These experimental results are presented to confirm the effectiveness and implementation of the proposed phase current reconstruction method. The proposed system can be more compact, robust, and cost effective than conventional counterparts, and be suited for vehicle applications.

\section{REFERENCES}

[1] Z. Futang, C. Li, and Y. Chengliang, "Design and analysis of a novel multimode transmission for a HEV using a single electric machine," IEEE Trans. Veh. Technol., vol. 62, no. 3, pp. 1097-1110, Mar. 2013.

[2] L. Yu, and X. Longya, "The dual-current-loop controlled doubly fed induction motor for EV/HEV applications," IEEE Trans. Energy Convers., vol. 28, no. 4, pp. 1045-1052, Dec. 2013.

[3] L. Yen-Shin, L. Wei-Ting, L. Yong-Kai, and T. Jian-Feng, "Integrated inverter/converter circuit and control technique of motor drives with dual-mode control for EV/HEV applications," IEEE Trans. Power Electron., vol. 29, no. 3, pp. 1358-1365, Mar. 2014.

[4] Z. Ping, Z. Jing, L. Ranran, T. Chengde, and W. Qian, "Magnetic characteristics investigation of an axial-axial flux compound-structure PMSM used for HEVs," IEEE Trans. Magn., vol. 46, no. 6, pp. 21912194, Jun. 2010.

[5] A. Kolli, O. Bethoux, A. De Bernardinis, E. Laboure, and G. Coquery, "Space-vector PWM control synthesis for an H-bridge drive in electric vehicles," IEEE Trans. Veh. Technol., vol. 62, no. 6, pp. 2441-2452, Jul. 2013.

[6] S. P. Nikam, V. Rallabandi, and B. G. Fernandes, "A high-torquedensity permanent-magnet free motor for in-wheel electric vehicle application," IEEE Trans. Ind. Appl., vol. 48, no. 6, pp. 2287-2295, Nov./Dec. 2012.

[7] X. D. Xue, K. W. E. Cheng, J. K. Lin, Z. Zhang, K. F. Luk, T. W. Ng, and N. C. Cheung, "Optimal control method of motoring operation for SRM drives in electric vehicles," IEEE Trans. Veh. Technol., vol. 59, no. 3, pp. 1191-1204, Mar. 2010.

[8] M. Takeno, A. Chiba, N. Hoshi, S. Ogasawara, M. Takemoto, and M. A. Rahman, "Test results and torque improvement of the $50-\mathrm{kW}$ switched reluctance motor designed for hybrid electric vehicles," IEEE Trans. Ind. Appl., vol. 48, no. 4, pp. 1327-1334, Jul./Aug. 2012.

[9] Y. Hu, X. Song, W. Cao, and B. Ji, "New SR drive with integrated charging capacity for plug-in hybrid electric vehicles (PHEVs)," IEEE Trans. Ind. Electron., vol.61, no.10, pp. 5722- 5731, Oct. 2014.

[10] A. Chiba, M. Takeno, N. Hoshi, M. Takemoto, S. Ogasawara, and M. A. Rahman, "Consideration of number of series turns in switchedreluctance traction motor competitive to HEV IPMSM," IEEE Trans. Ind. Appl., vol. 48, no. 6, pp. 2333-2340, Nov./Dec. 2012.

[11] A. Chiba, Y. Takano, M. Takeno, T. Imakawa, N. Hoshi, M. Takemoto, and S. Ogasawara, "Torque density and efficiency improvements of a switched reluctance motor without rare-earth material for hybrid vehicles," IEEE Trans. Ind. Appl., vol. 47, no. 3, pp. 1240-1246, May/Jun. 2011

[12] K. Kiyota, T. Kakishima, H. Sugimoto, and A. Chiba, "Comparison of the test result and 3D-FEM analysis at the knee point of a $60 \mathrm{~kW}$ SRM for a HEV," IEEE Trans. Magn., vol. 49, no. 5, pp. 2291-2294, May 2013

[13] R. Madhavan, and B. G. Fernandes, "Axial flux segmented SRM with a higher number of rotor segments for electric vehicles," IEEE Trans. Energy Convers., vol. 28, no. 1, pp. 203-213, Mar. 2013.

[14] C. Hung-Chun, and L. Chang-Ming, "Development of a compact switched-reluctance motor drive for EV propulsion with voltageboosting and PFC charging capabilities," IEEE Trans. Veh. Technol., vol. 58 , no. 7 , pp. 3198-3215, Sep. 2009.
[15] F. Blaabjerg, P. C. Kjaer, P. O. Rasmussen, and C. Cossar, "Improved digital current control methods in switched reluctance motor drives," IEEE Trans. Power Electron., vol. 14, no. 3, pp. 563-572, May 1999.

[16] I. Kioskeridis and C. Mademlis, "Maximum efficiency in single-pulse controlled switched reluctance motor drives," IEEE Trans. Energy Convers., vol. 20, no. 4, pp. 809-817, Dec. 2005.

[17] N. H. Fuengwarodsakul, M. Menne, R. B. Inderka, and R. W. De Doncker, "High-dynamic four-quadrant switched reluctance drive based on DITC," IEEE Trans. Ind. Appl., vol. 41, no. 5, pp. 1232-1242. Sep./Oct. 2005.

[18] G. Pasquesoone, R. Mikail, and I. Husain, "Position estimation at starting and lower speed in three-phase switched reluctance machines using pulse injection and two thresholds," IEEE Trans. Ind. Appl., vol. 47, no. 4, pp. 1724-1731, Jul./Aug. 2011.

[19] L. Shen, J. Wu, and S. Yang, "Initial position estimation in SRM using bootstrap circuit without predefined inductance parameters," IEEE Trans. Power Electron., vol. 26, no. 9, pp. 2449-2456, Sep. 2011.

[20] C. Jun, and D. Zhiquan, "Sensorless control of switched reluctance motor based on phase inductance vectors," IEEE Trans. Power Electron., vol. 27, no. 7, pp. 3410-3423, Jul. 2012.

[21] A. K. Jain and N. Mohan, "Dynamic modeling, experimental characterization, and verification for SRM operation with simultaneous two-phase excitation," IEEE Trans. Ind. Electron., vol. 53, no. 4, pp. 1238-1249, Aug. 2006.

[22] A. Jin-Woo, O. Seok-Gyu, M. Jae-Won, and H. Young-Moon, "A three-phase switched reluctance motor with two-phase excitation," IEEE Trans. Ind. Appl., vol. 35, no. 5, pp. 1067-1075, Sep./Oct. 1999.

[23] C. Younghoon, T. LaBella, and L. Jih-Sheng, "A three-phase current reconstruction strategy with online current offset compensation using a single current sensor," IEEE Trans. Ind. Electron., vol. 59, no. 7, pp. 2924-2933, Jul. 2012.

[24] G. Yikun, N. Fenglei, Y. Dapeng, and L. Hong, "Switching-state phase shift method for three-phase-current reconstruction with a single dclink current sensor," IEEE Trans. Ind. Electron., vol. 58, no. 11, pp. 5186-5194, Nov. 2011.

[25] S. Kai, Q. Wei, H. Lipei, and K. Matsuse. "An overmodulation method for PWM-inverter-fed IPMSM drive with single current sensor," IEEE Trans. Ind. Electron., vol. 57, no. 10, pp. 3395-3404, Oct. 2010.

[26] B. Metidji, N. Taib, L. Baghli, T. Rekioua, and S. Bacha, "Phase current reconstruction using a single current sensor of three-phase AC motors fed by SVM-controlled direct matrix converters," IEEE Trans. Ind. Electron., vol. 60, no. 12, pp. 5497-5505, Dec. 2013.

[27] B. Metidji, N. Taib, L. Baghli, T. Rekioua, and S. Bacha, "Novel single current sensor topology for venturini controlled direct matrix converters," IEEE Trans. Power Electron., vol. 28, no. 7, pp. 35093516, Jul. 2013.

[28] D. P. Marcetic and E. M. Adzic, "Improved three-phase current reconstruction for induction motor drives with dc-link shunt," IEEE Trans. Ind. Electron., vol. 57, no. 7, pp. 2454-2462, Jul. 2010.

[29] M. Bertoluzzo, G. Buja, and R. Menis, "Direct torque control of an induction motor using a single current sensor," IEEE Trans. Ind. Electron., vol. 53, no. 3, pp. 778-784, Jun. 2006.

[30] X. Changliang, L. Zhiqiang, and S. Tingna, "A control strategy for four-switch three-phase brushless DC motor using single current sensor," IEEE Trans. Ind. Electron., vol. 56, no. 6, pp. 2058-2066, Jun. 2009

[31] P. C. Kjaer and G. Gallegos-Lopez, "Single-sensor current regulation in switched reluctance motor drives," IEEE Trans. Ind. Appl., vol. 34, no. 3, pp. 444-451. May/Jun. 1998. 


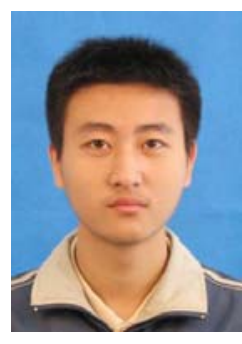

Chun Gan (S'14) received B.S. and M.S. degrees in power electronics and drives from China University of Mining and Technology, Jiangsu, China, in 2009 and 2012, respectively. $\mathrm{He}$ is currently working toward Ph.D. degree in the College of Electrical Engineering, Zhejiang University, Hangzhou, China.

His research interests include electrical motor drives, motor design, control with emphasis on switched reluctance motor sensorless technique, and optimization of the torque ripple and efficiency of the motor system.

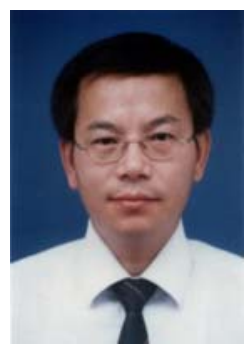

Jianhua Wu received the B.S. degree from Nanjing University of Aeronautics and Astronautics, China, and the M.S. and Ph.D. degrees from Huazhong University of Science and Technology, China, in 1983, 1991 and 1994, respectively, all in electrical engineering.

From 1983 to 1989, he was with Guiyang Electric Company as a Design Engineer. Since 2005, He has been a Professor at the College of Electrical Engineering, Zhejiang University, China. He developed the motor design software Visual EMCAD, which is widely used in China. His research interests are electric machine design and drives, including switched reluctance motors, permanent magnet machines for electric vehicle applications.

Dr. Wu is serving as the member of Electrical Steel of Chinese Society for Metals, the Small-power Machine Committee of China Electrotechnical Society, and the Standardization Administration of China.

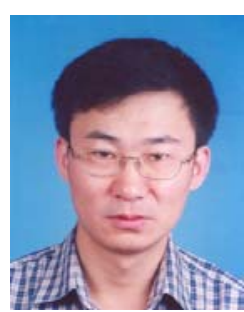

Shiyou Yang received his M.S. degree and Ph.D. degrees from Shenyang University of Technology, Liaoning, China, in 1990 and 1995, respectively, both in electrical engineering.

$\mathrm{He}$ is currently a Professor at the College of Electrical Engineering, Zhejiang University, Hangzhou, China. His research interests include computational electromagnetics.

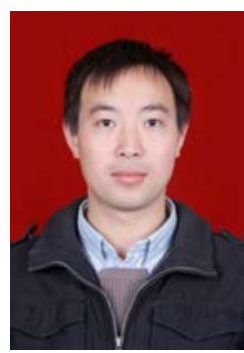

Yihua Hu (M'13) received the B.S. degree in electrical motor drives in 2003, and the Ph.D. degree in power electronics and drives in 2011, both from China University of Mining and Technology, Jiangsu, China. Between 2011 and 2013, he was with the College of Electrical Engineering, Zhejiang University as a Postdoctoral Fellow.

Between November 2012 and February 2013, he was an academic visiting scholar with the School of Electrical and Electronic Engineering, Newcastle University, Newcastle upon Tyne, UK. He is currently a research associate with the Department of Electronic \& Electrical Engineering, University of Strathclyde, Glasgow, UK. He has published more than 20 technical papers in leading journals and conference proceedings. His research interests include PV generation system, DC$\mathrm{DC} / \mathrm{DC}-\mathrm{AC}$ converters, and electrical motor drives. 